\title{
Changes of mycorrhizal colonization along moist gradient in a vineyard of Eger (Hungary)
}

\author{
Ádám DONKÓ, ${ }^{1 *}$ Gábor ZANATHY, ${ }^{1}$ Zsolt ERŐS-HONTI,${ }^{2}$ \\ Szabolcs VILLANGÓ, ${ }^{3}$ György Dénes BISZTRAY ${ }^{1}$ \\ ${ }^{1}$ Department of Viticulture, Faculty of Horticulture, Corvinus University of Budapest, \\ adam.donko@uni-corvinus.hu (*corresponding author) \\ ${ }^{2}$ Department of Botany and Soroksár Botanical Garden, Faculty of Horticulture, \\ Corvinus University of Budapest \\ ${ }^{3}$ Department of Oenology, Faculty of Food Science, Corvinus University of Budapest
}

Manuscript received 07. 12. 2014; revised 07. 30. 2014; accepted 08. 12. 2014

\begin{abstract}
The role of mycorrhizal fungi has special importance in the case of low soil moisture because the colonization of vine roots by mycorrhiza increases water and nutrient uptake and thus aids the avoidance of biotic and abiotic stresses of grape. Our aim was to investigate in the Eger wine region the changes of mycorrhizal colonization, water potential, and yield quality and quantity of grape roots at three altitudes, along a changing soil moist gradient. Our results show that the degree of mycorrhizal colonization is higher in drier areas, which supports the water and nutrient uptake of the host plant.
\end{abstract}

Keywords: mycorrhiza, grapevine, drought stress

\section{Introduction}

The changing climate can have adverse effects on agriculture. A quite serious effect is the increased length and frequency of extremely hot and dry periods during the summer, what may considerably alter the fruiting yield of the grape. Due to drought, the photosynthetic activity of the berries and the leaves is reduced $[11,14]$. Poni et al. (1994) found that drought stress causes more serious damage to the youngest vines. Mycorrhizal colonization is really important for plants like grape for this plant species has fewer fine roots that cannot net the soil intensively on their own [12]. The fungal partner (mycobiont) supports the water and nutrient uptake of the host plant while the mycobiont gets the carbohydrate necessary for their metabolism from the plant [31]. In the case of grape, the fungus colonizes the 
roots intracellularly, and it forms dichotomously-branching invaginations (arbuscules), i.e. the roots bear arbuscular mycorrhizae (AM). The large surface area of the arbuscules ensures robust nutrient exchange between the plants and the fungus and vice versa [28]. The efficiency of the symbiosis can be described not only through the degree of colonization but also with the number of arbuscules on the colonized root stage $[22,28]$. Mycorrhizal fungi are able to colonize different plants at the same time to form an interconnected physiological system, called common mycelia network $[13,30]$. This develops a nutrient and water transport system between the several species of the vineyard [3, 7]. Typically, there is sufficient fungus already in the soil of the vineyards, but we can deliberately increase the level of colonization of the rootstocks used for the grafting. Consequently, artificial inoculation of grafting rootstock is suggested to increase adaptation to the plantation site, which results in stronger initial growth $[2,15,21]$. This is especially important in the first year of the vineyard development [10]. Mycorrhizal fungi are normally occurring in the soil [6], but inoculation can directly increase the number of mycorrhiza near plant roots [4]. Inoculation plays a significant role in the success of plantation development, especially under dry edaphic and climatic conditions, as water and nutrient uptake are increased for the young vines. If soil sterilization has occurred previously, inoculation of new rootstock may also be recommended [18]. Inoculation of older, already producing plantations is not necessary. If the soil contains inoculates of the native mycorrhiza fungi, the artificial inoculation is not worthwhile [19]. Native mycorrhiza species are more effective than the artificially available inoculants, presumably because the native species have adapted to the local circumstances. A successfully producing vine indicates sufficient mycorrhizal colonization [29]. In extreme weather conditions - especially in case of drought -, the role of mycorrhizal fungi is more important: mycorrhizal colonization changes the physiological nature of vines [9]. Mycorrhizal colonization is inversely related to soil moisture: as soil moisture increases, the incidence of arbuscules decreases [29]. With mycorrhizal colonization, grapes have a higher tolerance to drought $[8,16]$. The effect on drought tolerance is related to the increased supply of soil moisture to the plants, osmotic regulation at the roots, and the altered hormone synthesis and transport [1]. In case of drought stress, the mycorrhizal colonization of the grapes increases [20, 25]. Where there are dry steep slopes and less fertile soils, there is a higher demand for mycorrhizal fungi to produce quality wines than in the case of more fertile or gently sloping soils having a more optimal retention of soil moisture [26, 32]. The aim of our experiment was to investigate the effect of inland water inundation - as a stress factor - of a two-year period (2011 and 2012) on the mycorrhiza colonization of grape roots, to study the effects of the inland water as stress factor, under field conditions. 


\section{Materials and methods}

The Eger wine region is situated on 22,160 hectares in the northeast part of Hungary. The Eger wine region has almost 1,000 years of grape growing tradition. Our experiment was carried out in a plantation next to the city of Eger, which is the centre of the wine region. Three sets of experimental blocks were delineated at three different elevations along the slope of the sample vineyard (Fig. 1.). Samples were taken from the same plots in the spring and autumn. In addition to mycorrhizal colonization, yield and the stum quality were measured. The vine variety investigated was a Pinot Noir grafted on Teleki-Kober 125 AA rootstock, planted in 2001. The lowest part of the plantation had not been cultivated for decades before the vine establishment because the roughly $1000 \mathrm{~m}^{2}$ area was often covered with standing water. The soil of the plantation is a Ramman brown soil, which is a clay type. Due to the high level of precipitation in 2010 (Tab. 1.), the low-lying area was covered with inland water until the end of 2012.

Tab. 1. Meteorological parameters

\begin{tabular}{|c|c|c|c|c|c|c|c|c|}
\hline \multicolumn{7}{|c|}{ Monthly precipitate (mm) } & \multirow{2}{*}{$\begin{array}{c}\text { Yearly } \\
\text { precipitate } \\
(\mathbf{m m})\end{array}$} & \multirow{2}{*}{$\begin{array}{c}\text { Solar } \\
\text { heat } \\
(\operatorname{Tmax} \geq \\
\left.\mathbf{3 0}^{\circ} \mathrm{C}\right) \\
\end{array}$} \\
\hline Year & March & April & May & June & July & August & & \\
\hline 2010 & 10.2 & 53.5 & 167 & 98.9 & 166.4 & 62.5 & 924.6 & 24 \\
\hline 2011 & 35.6 & 10.5 & 26.2 & 68.9 & 90.2 & 20.7 & 349.2 & 25 \\
\hline 2012 & 0 & 40.1 & 38.8 & 75 & 107.6 & 5.4 & 493.5 & 42 \\
\hline
\end{tabular}

Reference: www.metnet.hu

Block I was near the part of the vineyard covered with standing water. Blocks II and III were set progressively higher up the slope with the last one near the top of the vineyard, i.e. the crest of the slope. Each block contained four replications ( $4 \times 25$ vines in each block). 


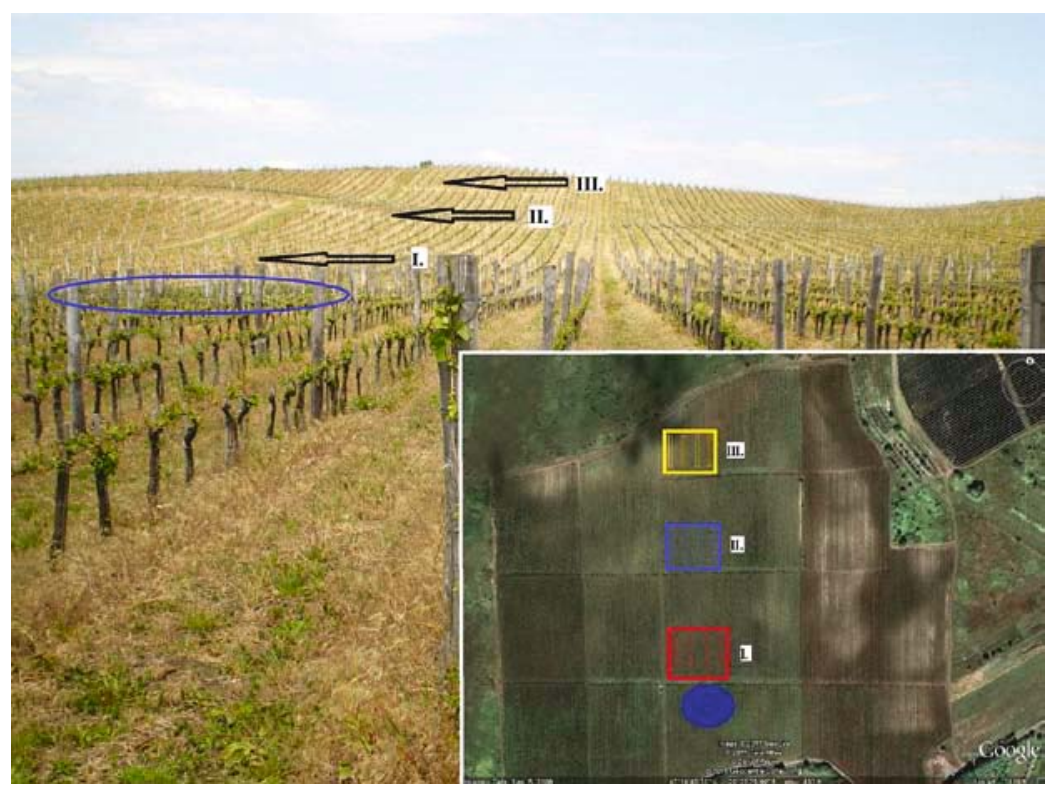

Fig. 1. The experimental blocks in the Eger wine-region

In 2011 and 2012, fine root samples were collected from 16 vine plants from each block after flowering and in the autumn (so, altogether 196 grapevines were sampled). The fine root segments were washed in distilled water, and stored in $70 \%$ ethanol. Before examination, the root sections were stained with aniline blue. Mycorrhizal colonization was determined on randomly selected root fragments using the method described by McGonigle et al. (1990) as modified by Schreiner (2003). The roots were mounted in parallel lines on the microscope slides. The proportion of colonization was determined under light microscope by assessing intersections between root fragments and the eyepiece micrometer at $2.5 \mathrm{~mm}$ increments. If the fragment contained hyphae and/or arbuscules, it was defined as colonized. Because the efficiency of the symbiosis can be described best by the number of arbuscules on the colonized root stage [22, 27], we also documented the number of arbuscules together with the colonization evaluation for the investigated root sections. For 2012, the water potential of the grapes was measured at the three different elevations [24]. We used the SPKM 4000 (Skye Instruments Ltd.) pressure chamber instrument, which can measure between 0 and $4 \mathrm{mPa}$. The measurement was carried out in the summer of 2012, on a hot, sunny midday. We collected eight leaves from each block.

The results were statistically analysed with the SPSS programme's One-Way Anova and Fisher's exact tests. 


\section{Results and discussion}

However, the precipitation of 2010 (Tab. 1.) induced inland water till the end of 2012; the standing water and high water table destroyed all the grape plants in this area. The lowest lying block (Block I) was adjacent to this area so as to describe the significant differences regarding water potential of the plants between the three blocks (Tab. 2.). This is evident in the relief photo of the area.

Tab. 2. Water potential of the leaves (2012.08.19.)

\begin{tabular}{|c|c|c|c|}
\hline Blocks & \multicolumn{3}{|c|}{ Water potential (mPa) } \\
\hline I. & \multicolumn{3}{|c|}{1.31} \\
\hline II. & \multicolumn{3}{|c|}{1.41} \\
\hline III. & \multicolumn{3}{|c|}{1.54} \\
\hline \multirow{2}{*}{ Sign. ${ }^{l}$} & I-II & I-III & II-III \\
\cline { 2 - 4 } & + & $* *$ & $*$ \\
\hline
\end{tabular}

${ }^{I}$ Difference between the averages investigated with Tukey-test $(\mathrm{p}<0.05)$

n.s. $=$ no significant difference; $+=\mathrm{p}<0.1 ; *=\mathrm{p}<0.05 ; * *=\mathrm{p}<0.01 ; * * *=\mathrm{p}<0.005$

The results show that in the spring of 2011 there was difference in the number of arbuscules between blocks (Tab. 3). The mycorrhizal and arbuscular colonization did not differ significantly.

Tab. 3. Investigation of the root segments, 2011 spring

\begin{tabular}{|c|c|c|c|c|c|c|c|c|c|}
\hline Blocks & \multicolumn{2}{|c|}{ Colonization (\%) } & \multicolumn{2}{|c|}{$\begin{array}{c}\text { Arbuscular colonization } \\
(\%)\end{array}$} & \multicolumn{2}{|c|}{$\begin{array}{c}\text { Number of arbuscules } \\
\text { (pieces) }\end{array}$} \\
\hline \multirow{2}{*}{ I. } & \multicolumn{2}{|c|}{76} & \multicolumn{3}{|c|}{30} & \multicolumn{3}{c|}{59} \\
II. & \multicolumn{2}{|c|}{79} & \multicolumn{3}{|c|}{36} & \multicolumn{3}{c|}{78} \\
III. & \multicolumn{2}{|c|}{81} & \multicolumn{3}{|c|}{34} & \multicolumn{3}{c|}{81} \\
\hline \multirow{2}{*}{ Sign. ${ }^{l}$} & I-II & I-III & II-III & I-II & I-III & II-III & I-II & I-III & II-III \\
\cline { 2 - 10 } & n.s. & n.s. & n.s. & n.s. & n.s. & n.s. & + & + & n.s. \\
\hline
\end{tabular}

${ }^{\mathrm{I}}$ Difference between the averages investigated with Tukey-test $(\mathrm{p}<0.05)$

n.s. $=$ no significant difference; $+=\mathrm{p}<0.1 ; *=\mathrm{p}<0.05 ;{ }^{* *}=\mathrm{p}<0.01 ; * * *=\mathrm{p}<0.005$

During the investigation of the roots sampled in the autumn of 2011, we found significant difference in colonization between blocks I and II, I and III, and in the number of arbuscules we again found difference between blocks I and II and I and 
III (Tab. 4). The arbuscular colonization percentage did not show significant difference between the blocks.

Tab. 4. Investigation of the root segments, 2011 autumn

\begin{tabular}{|c|c|c|c|c|c|c|c|c|c|}
\hline Blocks & \multicolumn{3}{|c|}{ Colonization (\%) } & \multicolumn{3}{|c|}{$\begin{array}{c}\text { Arbuscular colonization } \\
(\%)\end{array}$} & \multicolumn{3}{|c|}{$\begin{array}{c}\text { Number of arbuscules } \\
\text { (pieces) }\end{array}$} \\
\hline I. & \multicolumn{3}{|c|}{53} & \multicolumn{3}{|c|}{58} & \multicolumn{3}{|c|}{91} \\
\hline II. & \multicolumn{3}{|c|}{64} & \multicolumn{3}{|c|}{66} & \multicolumn{3}{|c|}{158} \\
\hline III. & \multicolumn{3}{|c|}{73} & \multicolumn{3}{|c|}{62} & \multicolumn{3}{|c|}{140} \\
\hline \multirow{2}{*}{ Sign. $^{l}$} & I-II & I-III & II-III & I-II & I-III & II-III & I-II & I-III & II-III \\
\hline & + & + & n.s. & n.s. & n.s. & n.s. & $*$ & $*$ & n.s. \\
\hline
\end{tabular}

We found differences between the blocks in the spring sampling of 2012 (Tab. 5). Our results show significantly higher rates of the mycorrhizal colonization and number of arbuscules in the higher altitude blocks than in the lowest lying block near the moist area of the vineyard.

Tab. 5. Investigation of the root segments, 2012 spring

\begin{tabular}{|c|c|c|c|c|c|c|c|c|c|}
\hline Blocks & \multicolumn{3}{|c|}{ Colonization (\%) } & \multicolumn{3}{|c|}{$\begin{array}{c}\text { Arbuscular colonization } \\
(\%)\end{array}$} & \multicolumn{3}{|c|}{$\begin{array}{c}\text { Number of arbuscules } \\
\text { (pieces) }\end{array}$} \\
\hline I. & \multicolumn{3}{|c|}{46} & \multicolumn{3}{|c|}{31} & \multicolumn{3}{|c|}{48} \\
\hline II. & \multicolumn{3}{|c|}{62} & \multicolumn{3}{|c|}{37} & \multicolumn{3}{|c|}{97} \\
\hline III. & \multicolumn{3}{|c|}{64} & \multicolumn{3}{|c|}{38} & \multicolumn{3}{|c|}{105} \\
\hline \multirow{2}{*}{ Sign. ${ }^{l}$} & I-II & I-III & II-III & I-II & I-III & II-III & I-II & I-III & II-III \\
\hline & $*$ & $* *$ & n.s. & n.s. & n.s. & n.s. & $*$ & $*$ & n.s. \\
\hline
\end{tabular}

Our results are in agreement with those of [26, 32]: the grape definitely needs the support of the mycorrhizal colonization on dry and sloped sites, as well as on those of low humus content. The results also confirm those $[8,16]$ who observed that drought periods with low precipitation can increase the amount of mycorrhizal colonization and therefore contribute to the vine tolerance of drought stress. Almost every investigation has found a higher number of arbuscules at higher elevations of the slopes. At the beginning of our work, the first block was adjacent to the inland-water-covered part of the vineyard, so, the soil water content was high 
and the soil gas content was low for the grapevines. These conditions have probably contributed to the low colonization level of these vine roots as well. Here, the vine plants may not need the help of the fungus to improve their water uptake. As soil moisture content is more available to the vines, the frequency of the arbuscules decreases [29]. Mycorrhizal colonization is less common in the case of irrigated vineyards where soil moisture is maintained near an optimal level [27]. Supporting water uptake is not the only function of the hyphae. The arbuscularmycorrhizal fungus has an effect on the water storage capacity of the soil and the stability of soil aggregates by the ability of fungal hyphae to entwine the soil particles with the aid of a special compound, glomalin, produced by arbuscular mycorrhizal fungi [34]. 2012 was a dry year in Eger and the standing inland water evaporated from the lowest part of the vineyard. In the autumn of 2012, we did not measure significant difference in the number of arbuscules between the three blocks, but in terms of arbuscular colonization we saw significant differences in the favour of Block I. (Tab. 6).

Tab. 6. Investigation of the root segments, 2012 autumn

\begin{tabular}{|c|c|c|c|c|c|c|c|c|c|}
\hline Blocks & \multicolumn{3}{|c|}{ Colonization (\%) } & \multicolumn{3}{|c|}{$\begin{array}{c}\text { Arbuscular colonization } \\
\text { (\%) }\end{array}$} & \multicolumn{3}{|c|}{$\begin{array}{l}\text { Number of arbuscules } \\
\text { (pieces) }\end{array}$} \\
\hline I. & \multicolumn{3}{|c|}{75} & \multicolumn{3}{|c|}{44} & \multicolumn{3}{|c|}{72} \\
\hline II. & \multicolumn{3}{|c|}{74} & \multicolumn{3}{|c|}{32} & \multicolumn{3}{|c|}{69} \\
\hline III. & \multicolumn{3}{|c|}{82} & \multicolumn{3}{|c|}{30} & \multicolumn{3}{|c|}{75} \\
\hline \multirow{2}{*}{ Sign. ${ }^{l}$} & I-II & I-III & II-III & I-II & I-III & II-III & I-II & I-III & II-III \\
\hline & n.s. & n.s. & n.s. & + & $*$ & n.s. & n.s. & n.s. & n.s. \\
\hline
\end{tabular}

${ }^{I}$ Difference between the averages investigated with Tukey-test $(\mathrm{p}<0.05)$ n.s. $=$ no significant difference; $+=p<0.1 ; *=p<0.05 ; * *=p<0.01 ; * * *=p<0.005$

Table 7 shows us the comparison of the initial and the last examined periods. The changes marked in bold numbers in the case of Block I are quite important in the context of the decrease of the inland water during the two-year period. In accordance with [25], the frequency of the arbuscules tends to indicate the efficiency of interaction between grape and fungus. Due to the mycorrhizal colonization, grapes have a higher tolerance to drought $[8,16]$; so in the case of our open-field trial, the results are confirmed. 
Tab. 7. Comparison of the investigated blocks

\begin{tabular}{|c|c|c|c|c|c|c|}
\hline \multicolumn{7}{|c|}{2011 spring and 2012 autumn } \\
\hline \multirow[t]{2}{*}{ Examined indices } & $\begin{array}{l}2011 / \\
\text { spring }\end{array}$ & $\begin{array}{l}2012 / \\
\text { autumn }\end{array}$ & $\begin{array}{l}2011 / \\
\text { spring }\end{array}$ & $\begin{array}{l}2012 / \\
\text { autumn }\end{array}$ & $\begin{array}{l}2011 / \\
\text { spring }\end{array}$ & $\begin{array}{l}2012 / \\
\text { autumn }\end{array}$ \\
\hline & I. & I. & II. & II. & III. & III. \\
\hline $\begin{array}{r}\text { Mycorrhizal } \\
\text { colonization (\%) }\end{array}$ & 76 & 75 & 79 & 74 & 81 & 82 \\
\hline $\begin{array}{r}\text { Arbuscular } \\
\text { colonization (\%) }\end{array}$ & 30 & 44 & 36 & 32 & 34 & 30 \\
\hline $\begin{array}{r}\text { Number of } \\
\text { arbuscules (pieces) }\end{array}$ & 59 & 72 & 78 & 69 & 81 & 75 \\
\hline
\end{tabular}

Most likely, the decrease of the soil moisture content contributed to the increased arbuscular colonization. Moreover, because of the previously unfavourable soil conditions, the nutrient uptake was limited in the first two years, and the increased AM colonization enabled the uptake of the previously unavailable nutrients (due to the saturated state of the soil) to nutrients available to the vines. Our results regarding the mycorrhizal colonization correlate with the measured yields. In 2011, the yield, the number of bunches and the average bunch weight was significantly lower in the case of Block I than the in the case of the others (Tab. 7). The differentiation of buds occurs in the previous year (Bényei et al. 1999), so the unfavourable circumstances in 2010 (lack of air in the soil, inland water inundation and less sunlight (due to overcast and cloudy skies)) had a negative effect on the number of bunches and yield in the following year.

Tab. 8. Yield, 2011

\begin{tabular}{|c|c|c|c|c|c|c|c|c|c|}
\hline \multirow{2}{*}{ Blocks } & \multicolumn{2}{|c|}{$\begin{array}{c}\text { Averaged weight } \\
\text { of the bunches (g) }\end{array}$} & \multicolumn{2}{c|}{$\begin{array}{c}\text { Number of bunches } \\
\text { (bunch/vine) }\end{array}$} & \multicolumn{3}{c|}{$\begin{array}{c}\text { Yield of 16 vines } \\
(\mathrm{kg})\end{array}$} \\
\hline I. & \multicolumn{2}{|c|}{106.4} & \multicolumn{2}{|c|}{11.4} & \multicolumn{3}{c|}{19.4} \\
II. & \multicolumn{2}{|c|}{138.3} & \multicolumn{2}{|c|}{18.4} & \multicolumn{3}{c|}{40.9} \\
III. & \multicolumn{2}{|c|}{148.3} & \multicolumn{2}{c|}{15.6} & \multicolumn{2}{c|}{37.1} \\
\hline \multirow{2}{*}{ Sign. ${ }^{2}$} & I-II & I-III & II-III & I-II & I-III & II-III & I-II & I-III & II-III \\
\cline { 2 - 10 } & $*$ & $* *$ & n.s. & $* * *$ & $* *$ & n.s. & $* *$ & $* *$ & n.s. \\
\hline
\end{tabular}

${ }^{I}$ Difference between the averages investigated with Tukey-test $(\mathrm{p}<0.05)$ n.s. $=$ no significant difference; $+=\mathrm{p}<0.1 ; *=\mathrm{p}<0.05 ; * *=\mathrm{p}<0.01 ; * * *=\mathrm{p}<0.005$ 
Tab. 9. Yield, 2012

\begin{tabular}{|c|c|c|c|c|c|c|c|c|c|}
\hline Blocks & \multicolumn{3}{|c|}{$\begin{array}{l}\text { Averaged weight of } \\
\text { the bunches }(\mathrm{g})\end{array}$} & \multicolumn{3}{|c|}{$\begin{array}{l}\text { Number of bunches } \\
\text { (bunch/vine) }\end{array}$} & \multicolumn{3}{|c|}{$\begin{array}{l}\text { Yield of } 16 \text { vines } \\
\qquad(\mathrm{kg})\end{array}$} \\
\hline I. & \multicolumn{3}{|c|}{75} & \multicolumn{3}{|c|}{44} & \multicolumn{3}{|c|}{72} \\
\hline II. & \multicolumn{3}{|c|}{74} & \multicolumn{3}{|c|}{32} & \multicolumn{3}{|c|}{69} \\
\hline III. & \multicolumn{3}{|c|}{82} & \multicolumn{3}{|c|}{30} & \multicolumn{3}{|c|}{75} \\
\hline \multirow{2}{*}{ Sign. ${ }^{l}$} & I-II & I-III & II-III & I-II & I-III & II-III & I-II & I-III & II-III \\
\hline & n.s. & n.s. & n.s. & + & $*$ & n.s. & n.s. & n.s. & n.s. \\
\hline
\end{tabular}

I Difference between the averages investigated with Tukey-test $(\mathrm{p}<0.05)$

n.s. $=$ no significant difference; $+=\mathrm{p}<0.1 ; *=\mathrm{p}<0.05 ; * *=\mathrm{p}<0.01 ; * * *=\mathrm{p}<0.005$

Micorrhyza fungi help not only water uptake but nutrient uptake as well [25]; so, the low number of arbuscules correlates with the reduced differentiation of the buds. The drier weather of 2011 and the disappearance of the inland water had a positive effect on bud differentiation. Yet, more bunches were observed at higher altitudes than were counted on the inland-water-covered block, but the yield was not found to be significantly different (Tab. 9). The regeneration of the vine is indicated by increases in the number of bunches and so the increased activity of the mycorrhiza measured as the number of arbuscules.

\section{Conclusion}

The results of our experiment were confirmed by results from other experts, which had been carried out in most cases under greenhouse conditions. Our work was a field trial and its importance is that mycorrhizal colonization was investigated under the effect of more extreme conditions and predictions from controlled experiments were confirmed in the actual vineyard site and across its variable soil. The results show the relevance of the microorganisms (in this case, the mycorrhizal fungi) in the balanced life of the grapevine, especially under extreme weather and site conditions, and in the practice of the organic farming.

\section{Acknowledgement}

Our work was supported by TÁMOP grants (TÁMOP-4.2.2/B-10/1-20100023-, TÁMOP- 4.2.1.B-09/1/KMR). 


\section{References}

[1] Augé, R. M. (2001), Water relations, drought and vesicular-arbuscular mycorrhizal symbiosis, Mycorrhiza 11, 3-42.

[2] Aguín, O., Mansilla, P., Vilariño, A., Sainz, M. (2004), Effects of mycorrhizal inoculation on root morphology and nursery production of three grapevine rootstocks, American Journal of Enology and Viticulture 55(1), 108-111.

[3] Baumgartner, K. (2003), Why and how. Encouraging beneficial AM fungi in vineyard soil, Practical Winery and Vineyard 14, 57-60.

[4] Bavaresco, L., Gatti, M., Zamboni, M., Fogher, C., Ferrari, F. (2010), Role of artificial mycorrhization on iron uptake in calcareous soils, on stilbene root synthesis and in other physiological processes in grapevine, $33^{\text {rd }}$ OIV World Congress of Vine and Wine. $8^{\text {th }}$ General Assembly of the OIV, 20-25 June 2010, Tbilisi, Georgia, 8.

[5] Bényei, F., Lőrincz, A., Sz. Nagy, L. (1999), Szőlőtermesztés. Mezőgazda Kiadó,Budapest.

[6] Cahural, J. Y. (2004), Mycorrhizae in grapevine. A review. Progrčs Agricole et Viticole, Montpellier 121(2), 31-36.

[7] Cheng, X., Baumgartner, K. (2005), Overlap of grapevine and cover crop roots enhances interactions among grapevines, cover crops, and arbuscular mycorrhizal fungi. In: Christensen, P., Smart, D. (eds.), Proceedings of the Soil Environment and Vine Mineral Symposium, 29-30 June 2004, San Diego, CA - American Society of Enology and Viticulture, Davis, CA, USA, 171-174.

[8] Davies, F. T., Potter, J. R., Linderman, R. G. (1992), Mycorrhiza and repeated drought exposure affect drought resistance and extraradical hyphae development of pepper plants independent of plant size and nutrient content, Plant Physiology 139(3), 289-294.

[9] Dell'Amico, J., A. Torrecillas, P. Rodriguez, Morte, A., Sanchez-Blanco, M. J. (2002), Responses of tomato plants associated with the arbuscular mycorrhizal fungus Gloumus clarum during drought and recovery, Journal of Agricultural Science 138, 387-393.

[10] Donkó, Á., Zanathy, G., Erős-Honti, Zs., Gál, Cs., Göblyös, J., Bisztray, Gy. D. (2013), Telepítéskor végzett mesterséges mikorrhizálás eredményessége a Kunsági borvidéken, Kertgazdaság 45(1), 20-28.

[11] Eibach, R., Alleweidt, G., (1984), Einfliß der Wasserversorgung auf Wachstum, Vitis 23, $11-20$.

[12] Eissenstat, D. M. (1992), Costs and benefits of constructing roots of small diameter, Plant Nutrition 15(6-7), 763-782.

[13] Francis, R., Read, D. J. (1984), Direct transfer of carbon between plants connected by vesicular arbuscular mycorrhizal mycelium, Nature 307, 53-56.

[14] Kounduras, S., Tsialtas, T., Zioziou, E., Nikolaou, N. (2008), Rootstock effects on the adaptive strategies of grapevine (Vitis vinifera L. cv. Cabernet-Sauvignon) under contrasting water status: Leaf physiological and structural responses, Agriculture, Ecosystems and Environment 128, 86-96.

[15] Linderman, R. G., Davis, E. A. (2001), Comparative response of selected grapevine rootstocks and cultivars to inoculation with different mycorrhizal fungi, American Journal of Enology and Viticulture 52, 8-11.

[16] Marschner, H. (1997), Mineral nutrition of higher plants, Academic Press, London.

[17] McGonigle, T. P., Miller, M. H., Evans, D. G., Fairchild, G. L., Swan, J. A. (1990), A new method which gives an objective measure of colonization of roots by vesicular-arbuscular mycorrhizal fungi, New Phytologist 115, 495-501. 
[18] Menge, J. A., Raski, D. J., Lider, L. A., Johnson, E. L. V., Jones, N. O., Kissler, J. J., Hemstreet, C. L. (1983), Interactions between mycorrhizal fungi, soil fumigation, and growth of grapes in California, American Journal of Enology and Viticulture 34, 117-121.

[19] Meyer, A. H., Valentine, A. J., Botha, A., Archer, E., Louw, P. J. E. (2004), Young grapevine response and root colonisation following inoculation with arbuscular mycorrhizal fungi, South African Journal of Enology and Viticulture 25(1), 26-32.

[20] Nikolaou, N., Angelopoulos, K., Karagiannidis, N. (2003), Effects of drought stress on mycorrhizal and non-mycorrhizal Cabernet Sauvignon grapevine, grafted onto various rootstocks, Experimental Agriculture 39, 241-252.

[21] Omar, A. E. K. (2007), Rooting and growth response of grapevine nurslings to inoculation with arbuscular mycorrhizal fungi and irrigation intervals, Journal of Applied Horticulture $9(2), 108-111$.

[22] Pinkerton, J. N., Schreiner, R. P., Ivors, K. L., Vasconcelos, M. C. (2004), Effects of Mesocriconema xenoplax on Vitis vinifera and associated mycorrhizal fungi, Journal of Nematology 36(3), 193-201.

[23] Poni, S., Bernizzoni, F., Civardi, S., Gatti, M., Porro, D., Camin, F. (2009), Performance and water-use efficiency (single-leaf vs. whole-canopy) of well-watered and half-stressed splitroot Lambrusco grapevines grown in Po Valley (Italy), Agriculture, Ecosystems and Environment 129, 97-106.

[24] Scholander, P. F., Hammel, H. T., Hemmingsen, E. A., Bradstreet, E. D. (1964), Hydrostatic pressure and osmotic potential in leaves of mangroves and some other plants, Proceedings of the National Academy of Sciences, USA 52, 119-125.

[25] Schreiner, R. P. (2003), Mycorrhizal colonization of grapevine rootstocks under field conditions, American Journal of Enology and Viticulture 54(3), 143-149.

[26] Schreiner, R. P., Linderman, R. G. (2005), Mycorrhizal colonization in dryland vineyards of the Willamette Valley, Oregon, Small Fruits Review 4(3), 41-55.

[27] Schreiner, R. P. (2005), Mycorrhizas and mineral acquisition in grapevines. In: Christensen, L. P., Smart, D. R. (eds.), Proceedings of the Soil Environment and Vine Mineral Nutrition Symposium, American Society for Enology and Viticulture, Davis, 49-60.

[28] Schreiner, R. P. (2005), Spatial and temporal variation of roots, arbuscular mycorrhizal fungi, and plant and soil nutrients in a mature Pinot Noir (Vitis vinifera L.) vineyard in Oregon, Plant and Soil 276(1-2), 219-234.

[29] Schreiner, R. P., Tarara, J. M., Smithyman, R. P. (2007), Deficit irrigation promotes arbuscular colonization of fine roots by mycorrhizal fungi in grapevines (*Vitis vinifera* L.) in an arid climate, Mycorrhiza 17(7), 551-562.

[30] Selosse, M.-A., Richard, F., He, X., Simard, S. W. (2006), Mycorrhizal networks: des liaisons dangereuses? Tree 21(11), 621-628.

[31] Smith, S. E., Gianinazzi-Pearson, V., Koide, R., Cairney, J. W. G. (1994), Nutrient transport in mycorrhizas: structure, physiology and consequences for efficiency of the symbiosis, Plant Soil 159, 103-113.

[32] Sweet, R. M., Schreiner, R. P. (2010), Alleyway cover crops have little influence on Pinot Noir grapevines (Vitis vinifera L.) in two Western Oregon vineyards, American Journal of Enology and Viticulture 61(2), 240-252.

[33] Valentine, A. J., Mortimer, P. E., Lintnaar, A., Borgo, R. (2006), Drought responses of arbuscular mycorrhizal grapevines, Symbiosis 41(3), 127-133.

[34] Wright, S. F., Upadhyaya, A. (1998), A survey of soils for aggregate stability and glomalin, a glycoprotein produced by hyphae of arbuscular mycorrhizal fungi, Plant and Soil 198, 97-107. 